\title{
Geomorphometric comparison of DEMs built by different interpolation methods
}

\author{
Bartłomiej Szypuła \\ Department of Geomorphology, Faculty of Earth Sciences, University of Silesia in Katowice, Sosnowiec, Poland; \\ bartlomiej.szypula@us.edu.pl
}

\begin{abstract}
One of the most important stages of creating DEMs is the selection of a suitable interpolation algorithm. In this paper I decided to take a look at the most popular methods of data interpolation: Inverse Distance Weighting, Natural Neighbour, Spline, Radial Basis Functions, Local Polynomial and Kriging. As the research area served fragment $\left(20 \mathrm{~km}^{2}\right)$ of the Silesian Upland with diversified relief. I analysed visual effects (3D view and profiles), summarized the basic geomorphometric statistics (heights, local relief, slopes, aspects, curvatures) and an assessment of the vertical accuracy of developed models (RMSE and result conformity) have made. After conducted studies it can be stated, that the best interpolation methods for analyse of the relief are Natural Neighbour and Kriging, because they do not create any artefacts.

Key words: DEM, LiDAR, geomorphometry, interpolation method, Silesian Upland
\end{abstract}

\section{Introduction}

The current broad access to world-wide digital elevation data such as SRTM (Farr et al. 2007, Nering 2009) or very high resolution digital elevation models (DEMs) such as Light Detection And Ranging (LiDAR, Wehr and Lohr 1999) makes, that geomorphologists more often reach for them and use as an important data source. Geomorphometry, which deals with the quantitative land-surface analysis (Pike et al. 2009) increasingly becomes an important part of geomorphological analysis, where the idea of objective research can be carried out.

Elevation data, no matter whether it comes from high-scanning (LiDAR), field measurements (GPS, tachymeter) or topo-maps digitalization, are collections of point data, i.e. a discrete, discontinuous. Visiting every location in a study area to measure the elevation, concentration, or magnitude of a phenomenon is usually difficult or expensive. Instead, one can measure the phenomenon at strategically dispersed sample locations, and predicted values can be assigned to all other locations. Input points can be either randomly or regularly spaced or based on a sampling scheme. Surface interpolation tools create a continuous prediction surface from sampled point values. Interpolation is collection of methods that allow estimate values for locations where no samples have been taken. Interpolation predicts values for cells in a raster from a limited number of sample data points. It can be used to predict unknown values for any geographic point data, such as elevation, rainfall, chemical concentrations, noise levels, and so on.

Many interpolation methods refer to Tobler's First Law of Geography (Tobler 1970). The basis of interpolation techniques is assumption, that spatially distributed objects are spatially correlated. Things that are close together tend to have similar characteristics, the values of points close to sampled points are more likely to be similar than those that are farther apart. Problems of interpolation methods are not new in the literature of the terrain models (Isaaks and Srivastava 1989, Wood and Fisher 1993, Declercq 1996, Carrara et al. 1997, Wise 1998, 2007, Zimmerman et al. 1999, Mitas and Mitasova 1999, Wilson and Gallant 2000, Sinha et al. 2002, Yang et al. 2004, Li et al. 2005, Yilmaz 2007, Kemp 2008) and it is known that DEMs can vary in quality depending on their method of creation (Wise 2011). It's just the choice of the appropriate interpolation method influ- 
ences the final result - digital elevation model, and followed derivatives and the resulting maps. In short - mismatched interpolation algorithm leads to false and low quality DEM, and this in turn leads to erroneous conclusions. Starting the work with elevation data one should be aware of the differences between interpolation algorithms in order to find the best one.

Modern GIS software lets better and more efficiently, than ever before, use the tools to create DEMs. Good quality DEM is basis of geomorphometry research, because as we know relatively small errors in elevation values in a DEM can produce large errors in the result maps. Florinsky (1998) pointed out that the quality of land surface parameters and objects depends on several factors, among other things, the DEM gridding algorithm. Erdogan (2009) concluded that the magnitude and distribution of errors in a DEM were strongly related to the interpolation algorithm. In this article I take a look at the six most common interpolation methods available in the ArcGIS for Desktop (10.5) software, which showed promising results at the initial stage.

There were two goals in this research:

1. The main aim was to answer: How different interpolation methods influence the creating of DEMs? How interpolation techniques change the final image of the DEMs? The first, the visual effect was taken into account, i.e. shapes and spatial distribution of landforms (morphography) of entire study area. Secondly, I wanted to check whether different interpolation methods affect the quantitative changes of the relief characteristics of the created DEMs, i.e. whether the characteristics of the geomorphometric variables are similar? This is important in the geomorphological analysis with a quantitative description and characteristics of the relief of the study area.

2. The second issue was checking how densely the height measurements in the study area need to sample that the resulting DEM reflects the character of the topography properly. Three experiments with pointsets were conducted and only one of them gave satisfactory results. I decided to random selection of points with the given distance interval between each other. It was turned out that it is possible to create a model with the much lower resolution, but with the similar geomorphometric properties.

Six gridded DEMs derived from set of height point data were compared. In the gridded DEMs the terrain is represented as elevations sampled on a regular grid (Weibel and Heller 1991). Sometimes there are problems with elevations that are sampled on a regular grid, which may undersample the terrain in rugged areas and oversample it in smooth areas for this kind of DEMs. I evaluated visual effect of the created DEMs (3D view and profile), compared to quantitative statistics (altitudes, local relief, slopes, aspects, curvatures, length and density of the contour lines) to verify their statistical variability and at the end I calculated the elevation accuracy (RMSE and result conformity) with the benchmark data (LiDAR DEM).

\section{Study area}

Study area is located in the south part of Poland in the Katowice Upland mesoregion, which is a part of the Silesian Upland (Kondracki 2001). The midpoint of the research area is situated at $50^{\circ} 21^{\prime} \mathrm{N}$ of latitude and at $19^{\circ} 05^{\prime} \mathrm{E}$ of longitude (Fig. 1). This area occupies $20.5 \mathrm{~km}^{2}$, which corresponds to the one sheet of Topographic Map of Poland 1:10,000 (1993). Geologically - the most important elevations of this area are made of resistant low-Triassic rocks, mainly dolomites, marls and sandstones, which are islands in the upper Carboniferous rocks (schists, mudstones and sandstones). The lowest places are covered with Pleistocene deposits of glacial sands and gravels (Biernat 1955).

The study area lies on the border of two major morphological units: Tarnogórski Threshold on the north and Bytom-Katowice Plateau on the south (Gilewska 1986). In addition, a more detailed subdivision includes this area to the Dąbrowa Basin, and the southern part of the area belongs to the Czeladź Upland (Karaś-Brzozowska 1960).

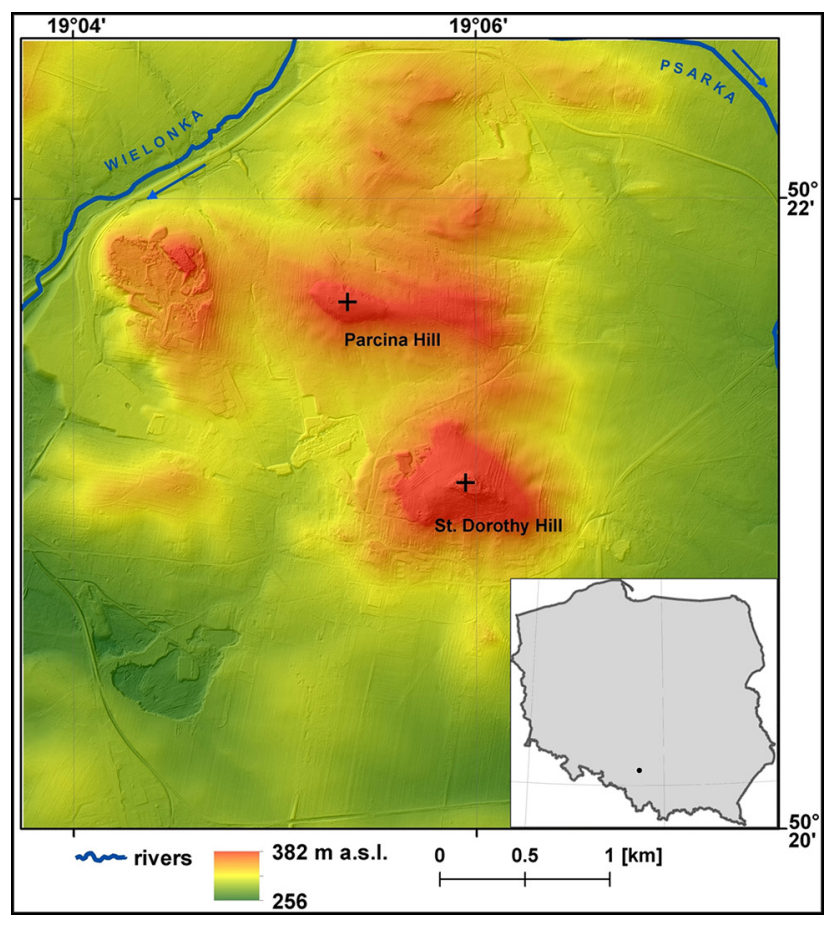

Fig. 1. Study area location and hypsometry 
The research area was chosen intentionally, it was supposed to be morphologically diversified and contain both elements of natural relief character, as well as related to human activity. The relief of the area is diverse - local relief is $125 \mathrm{~m}$ and the average altitude is $291 \mathrm{~m}$ a.s.l. There are the highest elevations St. Dorothy Hill (381 m a.s.l.) and Parcina Hill (355 $\mathrm{m}$ a.s.l.) in the central part of the area. In the NW part of the area Wielonka river flows, while at the NE edge - Psarka river. There are strong human impacts on relief in the western part of the area - it is an old coal mine area and the former sand pit.

Although the study area is not large, the goal was to select a place with diverse relief (both natural and anthropogenic), with elevation differences more than $100 \mathrm{~m}$ and with a well-recognized topography. That's all in order to easy catch artefacts and anomalies. In the light of such assumptions - the study area meets these requirements.

\section{Data and methods}

The elementary source data were binary files in LAS format, containing a cloud of points derived from airborne laser scanning (LiDAR), recorded in accordance with the standard 1.2 (ASPRS 2008). In addition to information about height and the metric system PUWG-1992 (EPSG:2180) coordinates, these files contain, among other things, class information for the point and the intensity of reflections in three ranges of the visible part of the electromagnetic radiation corresponding to the red, green and blue colours (RGB values), obtained from aerial photographs. The area of the analysis was generally in urban area, so the average density of the points was as high as 12 pts $\mathrm{m}^{-2}$ (standard II), and the average height accuracy is $\leq 0.2 \mathrm{~m}$ (CODGiK 2015, Wężyk 2014). Each LAS file corresponds to the one sheet of the map at scale of 1:1,250 (approx. $0.5 \times 0.5 \mathrm{~km}$ ), so these 64 files made up the entire research area.

The second source data set was the terrain model in ESRI ASCII Grid format and I called it LiDAR DEM. This DEM de facto is the result of the processing of the point cloud (LAS files) to the continuous raster surface with horizontal resolution of $1 \times 1 \mathrm{~m}$ and the same vertical accuracy (i.e. $\leq 0.2 \mathrm{~m}$ ). This format consists of header information containing a set of parameters, which can be used to geocode the data. Although the header includes the coordinates of the lower left corner of the area covered by the grid the elevation data are given as strings of elevations, in row by row, starting from the upper left point on the grid (ANU Fenner... 2008).

\section{Preparing the data}

In the first step, I filtered LAS files and left information about ground only, which according to the LAS 1.2 format corresponds to the classification of value 2 (ASPRS 2008). After this initial filtering, every LAS file contained average 2.4 million points, which corresponds to an average density of $7.5 \mathrm{pts}^{-2}$ for the entire research area. The Table 1 summarizes the basic statistics for the complete set of filtered LAS files data.

In this place, to avoid confusion, one should to explain - why and what did I use these LAS files for? My intention was not thinning or generalization dense LiDAR data, and I only needed a set of precise point elevation data with an accuracy similar to that derived from field measurements using RTK GPS class equipment. Due to the lack of such kind of data - I decided to obtain the selected elevation points from available LiDAR data.

Three experiments with selection of points in given distance interval between each other were conducted. The benchmark points with the distance interval of 100,200 and $500 \mathrm{~m}$ on the entire study area were generated. In the next step, inside the LiDAR points - the closest neighbour points of the bench-

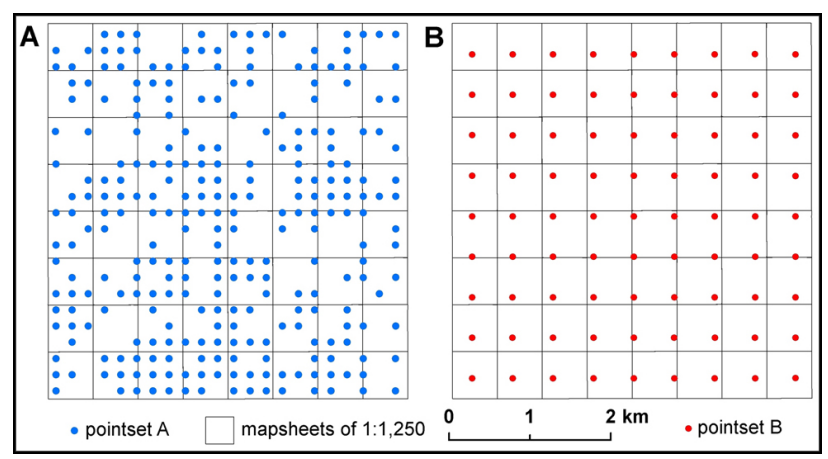

Fig. 2. Spatial distribution of the pointsets with the interval of $200 \mathrm{~m}(\mathrm{~A})$ and $500 \mathrm{~m}(\mathrm{~B})$

Table 1. Statistics of the LAS dataset

\begin{tabular}{|c|c|c|c|c|c|c|c|c|}
\hline \multirow{3}{*}{ Classification class } & \multicolumn{3}{|c|}{ Points } & \multicolumn{4}{|c|}{ Altitude[m] } & \multirow{3}{*}{ Variation coefficient } \\
\hline & \multirow{2}{*}{ Total number } & \multicolumn{2}{|c|}{ Mean density } & \multirow{2}{*}{$\min$} & \multirow{2}{*}{$\max$} & \multirow{2}{*}{ mean } & \multirow{2}{*}{$\mathrm{SD}^{*}$} & \\
\hline & & [pts $\left.\mathrm{m}^{-2}\right]$ & [pts km-2] & & & & & \\
\hline 2 (Ground) & 155979897 & 7.5 & $\begin{array}{l}7575 \\
252.2\end{array}$ & 256.23 & 381.51 & 291.39 & 6.04 & 2.07 \\
\hline
\end{tabular}

*SD - standarad deviation 


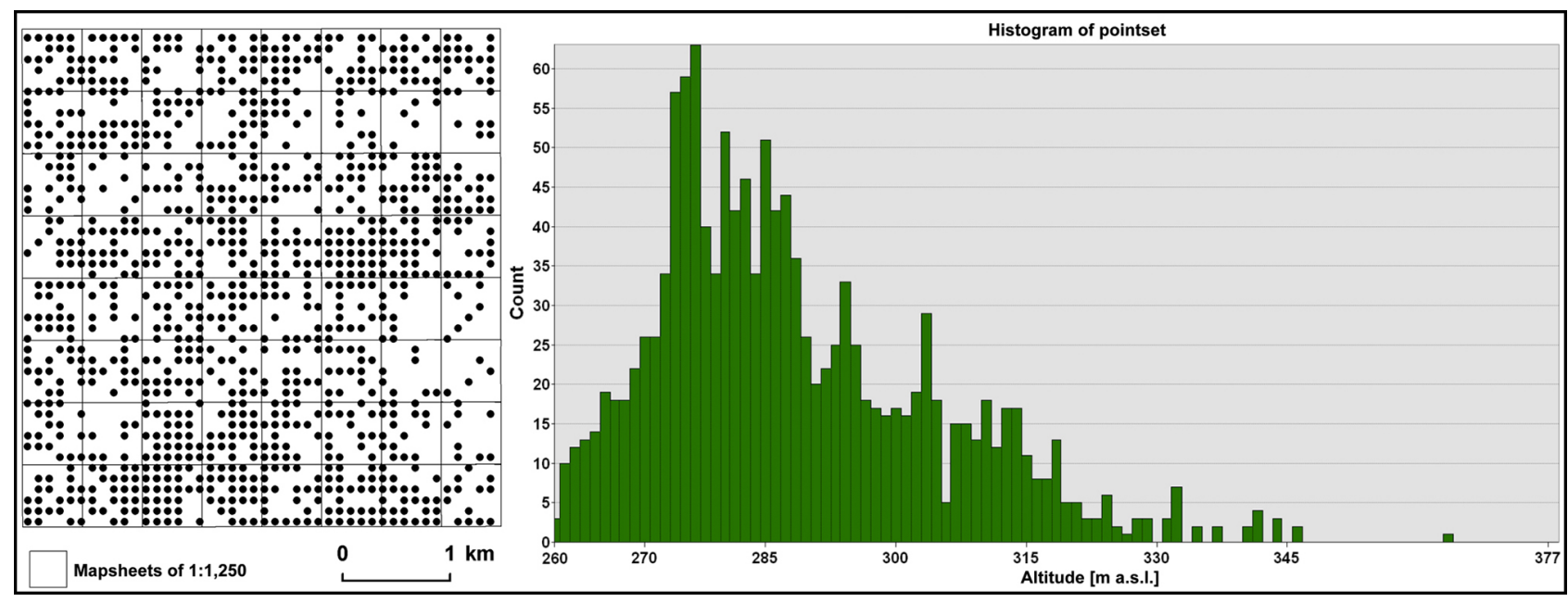

Fig. 3. Spatial and frequency distribution of the pointset

mark points were found. The average distance among the selected LiDAR points was: $103.5 \mathrm{~m}$ (for $100 \mathrm{~m}$ interval benchmark points), $209.1 \mathrm{~m}$ (for $200 \mathrm{~m}$ interval benchmark points) and $499.2 \mathrm{~m}$ for the third group. The spatial distribution of 200 and $500 \mathrm{~m}$ interval pointsets were shown in the Fig. 2 . These two groups of points did not yield good results in building of DEMs, because of poor quality of obtained DEMs.

I have been obtained satisfactory results only with the points of $100 \mathrm{~m}$ distance interval, with approximately regular distribution within the entire research area (Fig. 3). This pointset has become elementary elevation data, that next were used to create DEMs. It should be noted, that while the maximum height values are understated and SD values are three times higher than in the raw source (LiDAR) data (see Table 1 vs Table 2), whereas the minimum and averages values are almost the same. In addition, the Table 2 shows that the skewness values are positive, reflecting the right skewed distribution of data, i.e. the focus of the heights is at low values, and the dominant number of observations have a value below the average. Such prepared point elevation data was used to generate DEMs using different interpolation algorithms.

\section{Used interpolation methods}

There are a variety of ways to derive a prediction for each location and each way produces predictions using different calculations. The interpolation tools are generally divided into deterministic and geostatistical methods. The deterministic interpolation meth- ods assign values to locations based on the surrounding measured values and on specified mathematical formulas that determine the smoothness of the resulting surface (ESRI 2015). The deterministic methods that have been used here were: Inverse Distance Weighting (IDW), Natural Neighbour, Spline, Radial Basis Functions and Local Polynomial.

The geostatistical methods are based on statistical models that include autocorrelation (the statistical relationship among the measured points). Because of this, geostatistical techniques not only have the capability of producing a prediction surface but also provide some measure of the certainty or accuracy of the predictions. Geostatistical method that I have been used was Kriging.

All the methods which have been chosen are typical and in common use in available GIS software packages. Table 3 lists the interpolation algorithms available in commercial (ArcGIS, Surfer) and free (SAGA GIS, QGIS) software packages. Due to methodological limitations (i.e. using only point elevation data for interpolation) I decided not to use the ANUDEM method.

First method was Inverse Distance Weighted. IDW interpolation reflects that things that are close to one another are more alike than those that are farther apart. IDW assumes that each measured point has a local influence that diminishes with distance. This interpolation method determines cell values using a linearly weighted combination of a set of sample points. The weight is a function of inverse distance. The surface being interpolated should be that of a locational dependent variable. This method assumes

Table 2. Statistics of the pointset

\begin{tabular}{|c|c|c|c|c|c|c|c|c|}
\hline \multicolumn{2}{|r|}{ Points } & \multicolumn{4}{|c|}{ Altitude $[\mathrm{m}]$} & \multirow{2}{*}{ Variation coefficient } & \multirow{2}{*}{ Skewness } & \multirow{2}{*}{ Kurtosis } \\
\hline Total number & Mean density [pts $\mathrm{km}^{-2}$ ] & $\min$ & $\max$ & mean & SD & & & \\
\hline 1325 & 64.35 & 259.2 & 377.3 & 291.1 & 18.4 & 6.32 & 0.91 & 3.71 \\
\hline
\end{tabular}


Table 3. Interpolated methods available in GIS software

\begin{tabular}{|c|c|c|c|}
\hline ArcGIS (10.5) & Surfer (14.0) & SAGA GIS (5.0) & QGIS (2.18.12) \\
\hline $\begin{array}{l}\text { Raster Interpolation: } \\
\text { - Inverse Distance Weighted } \\
\text { - Global Polynomial } \\
\text { Interpolation } \\
\text { - Local Polynomial } \\
\text { Interpolation } \\
\text { - Radial Basis Functions } \\
\text { - Kriging } \\
\text { - CoKriging } \\
\text { - Empirical Bayesian } \\
\text { Kriging } \\
\text { - Areal Interpolation } \\
\text { - Natural Neighbor } \\
\text { - Spline } \\
\text { - Spline with Barriers } \\
\text { - Topo to Raster } \\
\text { (ANUDEM) } \\
\text { - Topo to Raster by File } \\
\text { - Trend } \\
\text { - Kernel Smoothing } \\
\text { - Diffusion Kernel }\end{array}$ & $\begin{array}{l}\text { Gridding methods: } \\
\text { - Data Metrics } \\
\text { - Inverse Distance } \\
\text { - Kriging } \\
\text { - Local Polynomial } \\
\text { - Minimum Curvature } \\
\text { - Modified Shepard's } \\
\text { - Method } \\
\text { - Moving Average } \\
\text { - Natural Neighbor } \\
\text { - Nearest Neighbor } \\
\text { - Polynomial Regression } \\
\text { - Radial Basis Function } \\
\text { - Triangulation with Linear } \\
\text { Interpolation }\end{array}$ & $\begin{array}{l}\text { Interpolation from Points: } \\
\text { - Angular Distance } \\
\text { Weighted } \\
\text { - Inverse Distance Weighted } \\
\text { - Modified Quadratic } \\
\text { Shepard } \\
\text { - Natural Neighbour } \\
\text { - Nearest Neighbour } \\
\text { - Triangulation } \\
\text { Spline interpolation: } \\
\text { - B-Spline Approximation } \\
\text { - Cubic Spline } \\
\text { Approximation } \\
\text { - Multilevel B-Spline } \\
\text { Interpolation } \\
\text { - Multilevel B-Spline } \\
\text { Interpolation (from Grid) } \\
\text { - Thin Plate Spline } \\
\text { - Thin Plate Spline (TIN) }\end{array}$ & $\begin{array}{l}\text { Interpolation method: } \\
\text { - Inverse Distance Weighted } \\
\text { - Nearest Neighbour } \\
\text { - Triangulated Irregular } \\
\text { Networks } \\
\text { - Statistics }\end{array}$ \\
\hline
\end{tabular}

that the variable being mapped decreases in influence with distance from its sampled location. The IDW is an inexact interpolation process. That is, the values that are interpolated won't exactly match the input points that are used. The IDW function should be used when the set of points is dense enough to capture the extent of local surface variation needed for analysis (Childs 2004).

Second method I used was Natural Neighbour. This interpolation finds the closest subset of input samples to a query point and applies weights to them based on proportionate areas to interpolate a value (Sibson 1981). It is also known as Sibson or "area-stealing" interpolation. Its basic properties are that it's local, using only a subset of samples that surround a query point, and interpolated heights are guaranteed to be within the range of the samples used. It does not infer trends and will not produce peaks, pits, ridges, or valleys that are not already represented by the input samples. The surface passes through the input samples and is smooth everywhere except at locations of the input samples.

Third method was Spline. The Spline interpolation tool uses an interpolation method that estimates values using a mathematical function that minimizes overall surface curvature, resulting in a smooth surface that passes exactly through the input points. Conceptually, the sample points extrude to the height of their magnitude. The basic form of the minimum curvature Spline interpolation imposes the following two conditions on the interpolant:

- the surface must pass exactly through the data points,

- the surface must have minimum curvature.
The cumulative sum of the squares of the second derivative terms of the surface taken over each point on the surface must be a minimum (Mitas and Mitasova 1988). There are two Spline types: regularized and tension. The regularized type creates a smooth, gradually changing surface with values that may lie outside the sample data range. The tension type controls the stiffness of the surface according to the character of the modelled phenomenon. It creates a less smooth surface with values more closely constrained by the sample data range (ESRI 2015).

In the fourth method one used Radial Basis Function to interpolate a surface. Radial Basis Functions are a series of exact interpolation techniques; that is, the surface must pass through each measured sample value (Carlson and Foley 1991). There are five different basis functions: Thin-plate spline, Spline with tension, Completely regularized spline, Multiquadric function and Inverse multiquadric function. Each basis function has a different shape and results in a different interpolation surface. In this case the best function turned out to be completely regularized spline. Radial basis functions are conceptually similar to fitting a rubber membrane through the measured sample values while minimizing the total curvature of the surface. The basis function you select determines how the rubber membrane will fit between the values (ESRI 2015).

The next method was Local Polynomial. This interpolation technique fits many polynomials, each within specified overlapping neighbourhoods. The search neighbourhood can be defined by using the size and shape, number of neighbours, and sector configuration. Local Polynomial interpolation fits the specified 
order (zero, first, second, third, and so on) polynomial using points only within the defined neighbourhood. The neighbourhoods overlap, and the value used for each prediction is the value of the fitted polynomial at the centre of the neighbourhood. Local Polynomial interpolation relies on the following assumptions:

- the samples were taken on a grid (that is, the samples are equally spaced),

- the data values, within the searching neighbourhood, are normally distributed.

In practice, most datasets will not conform to these assumptions, and in these cases, the predicted values will be affected but not as much as the prediction standard errors. To help you decide if the results in certain areas are reliable or not, LP provides a spatial condition number surface (ESRI 2015).

The last method was Kriging. This technique is an advanced geostatistical procedure that generates an estimated surface from a scattered set of eleva- tion points. Unlike other interpolation methods, to use the Kriging tool effectively involves an interactive investigation of the spatial behaviour of the phenomenon represented by the $z$-values before one selects the best estimation method for generating the output surface (ESRI 2015). Kriging assumes that the distance or direction between sample points reflects a spatial correlation that can be used to explain variation in the surface. The Kriging tool fits a mathematical function to a specified number of points, or all points within a specified radius, to determine the output value for each location. Kriging is a multistep process. It includes exploratory statistical analysis of the data, variogram modelling, creating the surface, and (optionally) exploring a variance surface (Royle et al. 1981, Oliver 1990).

In most cases, I used the default parameter settings. The Table 4 shows the properties of the main interpolation method parameters in the ArcGIS software.

Table 4. Parameters of used interpolation methods in ArcGIS

\begin{tabular}{ll}
\hline \multicolumn{1}{c}{ Interpolation method } & \multicolumn{1}{c}{ Settings in ArcGIS } \\
\hline IDW & $\begin{array}{l}\text { Power }(=2) \text { controls the significance of surrounding } \\
\text { points on the interpolated value. A higher power results } \\
\text { in less influence from distant points. It can be any real } \\
\text { number greater than } 0, \text { but the most reasonable results } \\
\text { will be obtained using values from } 0.5 \text { to } 3\end{array}$ \\
& $\begin{array}{l}\text { Search radius }(=12) \text { defines which and how many of the } \\
\text { input points will be used to interpolate the value for each } \\
\text { cell in the output raster. }\end{array}$
\end{tabular}

Natural Neighbour

Spline

Radial Basis Functions

Local Polynomial

Kriging
Spline type (= regularized) the type of spline to be used which yields a smooth surface and smooth first derivatives. Weight $(=0.1)$ Parameter influencing the character of the surface interpolation; it defines the weight of the third derivatives of the surface in the curvature minimization expression.

Number of points $(=12)$ the number of points per region used for local approximation

Kernel function (= completely regularized spline) the type of kernel that create the surface

Search neighbourhood ( $\max$ neighbours $=15$; $\min$ neighbours $=10$ ) $\mathrm{max} / \mathrm{min}$ number of features to be included in each sector

Exploratory trend surface analysis $(=100)$ value between 0 and 100 (value of 0 is the same as using the Global Polynomial Interpolation method)

Kernel function (= Expotential); Neighbourhood type (= standard); minimum neighbours $(=10)$; Bandwidth $(=$ 99.99)

Semivariogram properties (kriging method = ordinary; semivariogram model $=$ spherical) the semivariogram model to be used.

Search radius ( $=$ variable; number of points $=12$ ) uses a variable search radius in order to find a specified number of input sample points for the interpolation; number of points - an integer value specifying the number of nearest input sample points to be used to perform interpolation 


\section{Results and discussion}

DEMs were building in two resolutions:

- in resolution suggested by the ArcGIS program (the default is the rule, that the system will take the shortest side of the study area and divide it by 250 to estimate the output cell size),

- in resolution calculated after Hengl (2006) suggestions, who proposed the coarsest, the finest and the best (recommended) grid size (resolution).

Recommended grid resolution - this is a compromising resolution, usually set as the intermediate number between the coarsest and finest resolutions. I selected "best" option as the optimal. There are both proposals in the Table 5 .

Table 5. DEM resolutions recommended by Hengl (2006) and ArcGIS

\begin{tabular}{cccc}
\hline \multicolumn{3}{c}{ DEM resolution (cell size) } \\
\hline \multicolumn{3}{c}{ Hengl } & \multirow{2}{*}{ ArcGIS } \\
\cline { 1 - 3 } coarsest & finest & best & \\
\hline $12.5 \mathrm{~m}$ & $6.2 \mathrm{~m}$ & $10 \mathrm{~m}$ & $17.2 \mathrm{~m}$ \\
\hline
\end{tabular}

\section{Visual assessment of DEMs}

Among the different interpolation methods available in ArcGIS I selected only those that during the first interpolation tests showed the best results. All methods shown herein meet the minimum requirements for the interpolation techniques, i.e. faithfully show the relief distribution of the test area, taking into account the characteristic landforms. In the first step six DEMs compared with each other visually (Figs 4 and 5) and with the benchmark data (LiDAR DEM). As one can see the overall spatial distribution of the relief in the study area is similar, and the hypsometry image of the DEMs generally agree with LiDAR DEM. This indicates good representation of the samples, which include important details of the terrain surface.

There are many small hills called bull's eyes in the IDW model, which are the result of irregular distribution of elevation points. Unfortunately, the visual effect is artificial and negative (Fig. 5B).

The Natural Neighbour model is one of the best in this research. Although the basic equation used in Natural Neighbour interpolation is identical to the one used in IDW interpolation, the final surface is smoother (see Figs 5C and 6C). Probably it is because of creation of curved covers around the sample points. There are no artefacts.

The Spline method was the best in creating hills and summit places; this method intelligent smoothed surfaces that passes exactly through the input points. Unfortunately this method created a sizable artefact at the site of the former sand pit in the SW part of the area (see Figs 5D and 6D).

Another method - Radial Basis Function also quite well presented the image of the relief (Fig. 5E), but here and there were a lot of beads, which are clearly visible on the profile (Fig. 6E). Elevation areas are even more smoothed (flattened) than three previous methods.

Local Polynomial method, besides the two artefacts in the SW part (Fig. 5F), which have reached abnormally high values, very well characterized the area, which can also see on the profile (Fig. 6F).

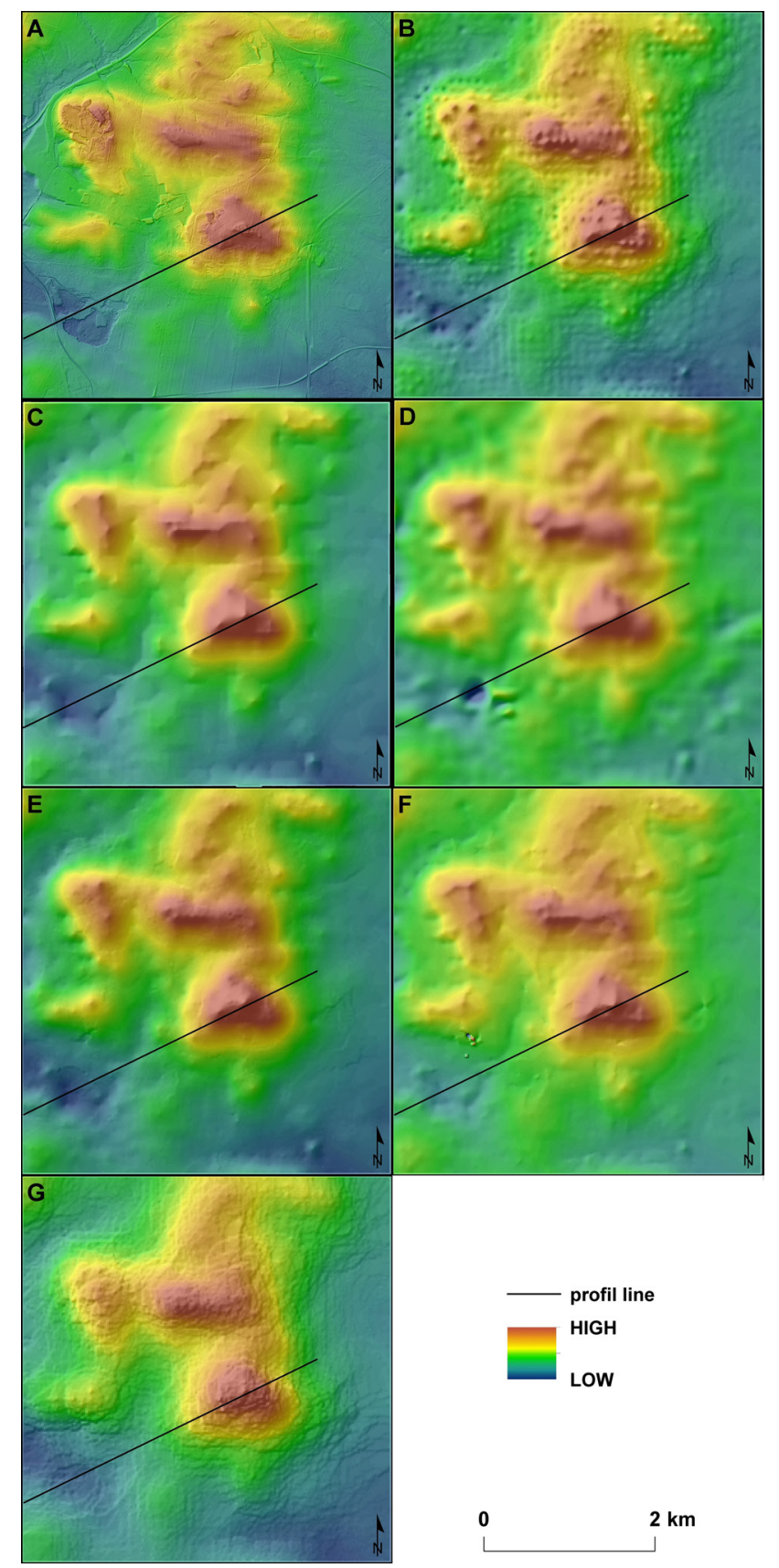

Fig. 4. Hypsometry of interpolated DEMs: A - LiDAR, B - IDW, C - Natural Neighbour, D - Spline, E - Kriging, F - Local Polynomial, G - Radial Basis Functions 

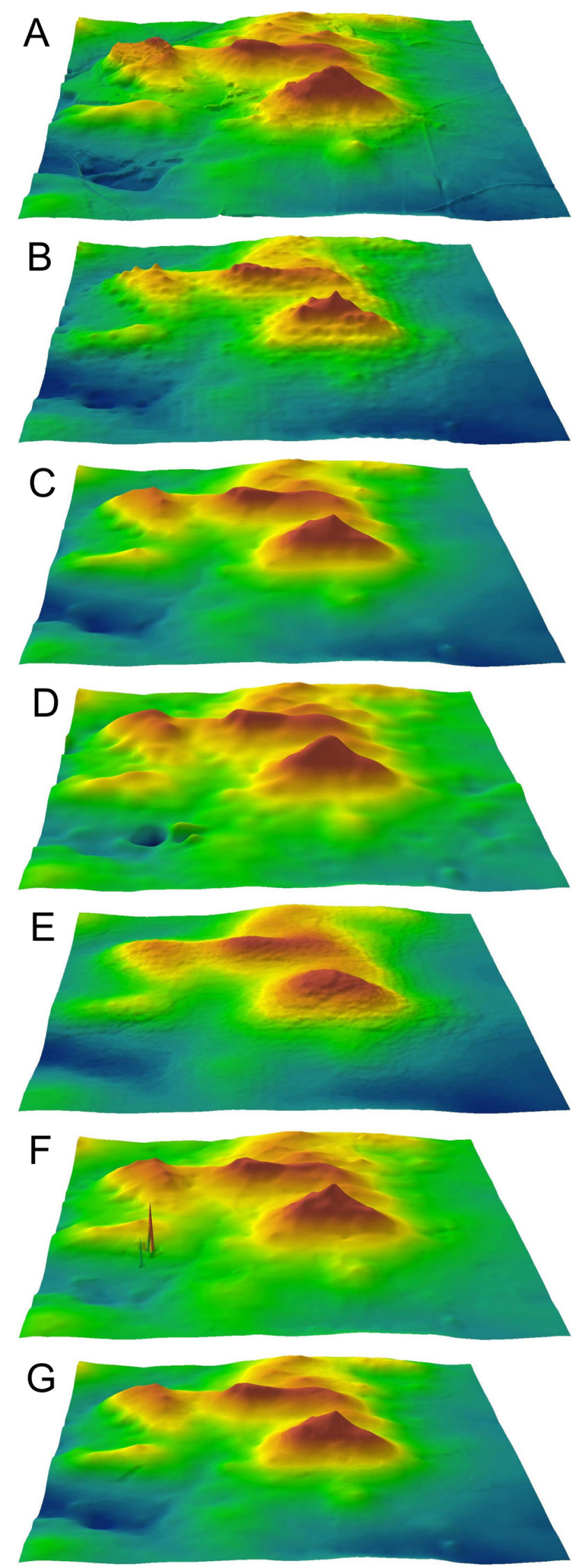

Fig. 5. 3D view of interpolated DEMs: A - LiDAR DEM, B - IDW, C - Natural Neighbour, D - Spline, E - Radial Basis Functions, F - Local Polynomial, G - Kriging
The last method - Kriging - proved to be by far the best in reconstructing the image of the relief (Fig. $5 \mathrm{G}$ ). Kriging gave a lot of small details (see Fig. 6A vs $6 \mathrm{G})$ and did not create any artefacts or other errors.

\section{Geomorphometric variables}

In the second step I focused on geomorphometric parameters. I was taken into account: altitude, local relief, slopes, aspects, curvatures and length and density of contour lines. The elevation values are available in the statistics of the raster data. Local relief is just the difference between the highest and the lowest elevation value (true height) in the specified search window. Slope tool calculates the maximum rate of change in value from the centre cell to its neighbours. Aspect tool is just the slope direction. The values of each cell in the output raster indicate the compass direction that the surface faces at that location (ESRI 2015). As the slope and aspect tools fit a plane to the $z$-values of a DEM $3 \times 3$ cell grid neighbourhood around the processing or centre cell, the true heights were calculating in the same $3 \times 3$ cell neighbourhood (Tabs. 6 and 7). The last parameters were length and density of contour lines generated with 1 meter interval. Length and the density of the contour lines express the degree of relief diversification, and some authors called it relief energy index (see Kozieł 2003).

Because of the different models resolution (Table 6) in comparisons of the geomorphometric statistics below I decided to collated models with the same resolution (i.e. $17 \times 17 \mathrm{~m}$, but after closer examination of Table 6 it is easy to see that the differences of variables between 10 and $17 \mathrm{~m}$ DEMs of IDW, Natural Neighbour and Kriging methods are small).

All the models, except Spline and Local Polynomial (Table 6) correctly reflected altitudes: min $256.3 \mathrm{~m}$, max $381.5 \mathrm{~m}$, mean $291.3 \mathrm{~m}$ and SD 19.6 $\mathrm{m})$, which were almost the same as in the LiDAR DEM (see the LiDAR source input data in Table 1). What is interesting, Spline and Local Polynomial models through their artefacts disturbed only altitude range, while the mean altitude and standard deviation of the altitude are consistent with the other models.

Local relief (Table 6) up ranges from 8.2 to 16.5 $\mathrm{m}$ (without Spline and Local Polynomial models), but the average value of 1.1 to $2.3 \mathrm{~m}$, and models in the same resolution (i.e. $17 \times 17 \mathrm{~m}$ ) differences were even smaller.

The maximum slopes for DEMs with a resolution of $17 \mathrm{~m}$ (without Spline and Local Polynomial models) took values from 13 to $21^{\circ}$, and the mean value common to all models $\left(2.5^{\circ}\right)$ and slope standard deviation $\left(1.9\right.$ to $2.8^{\circ}$ ) confirm the overall gentle nature of the landscape. 


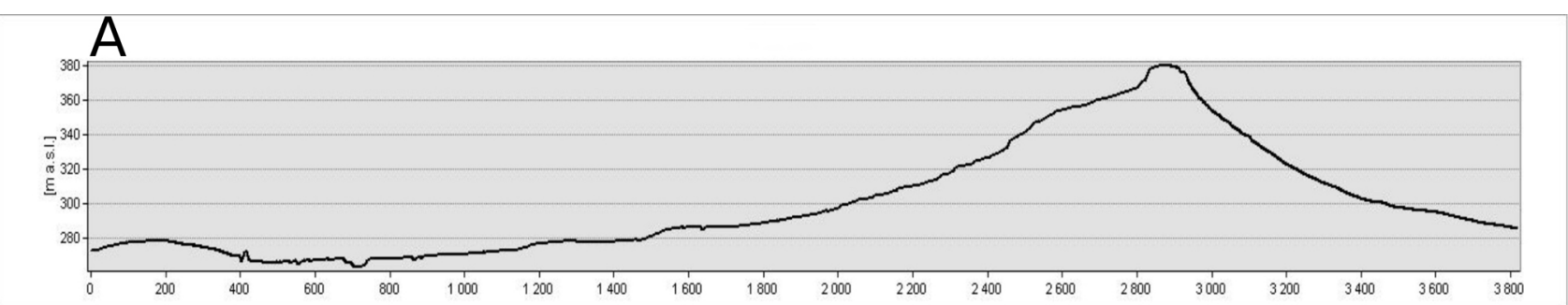

B
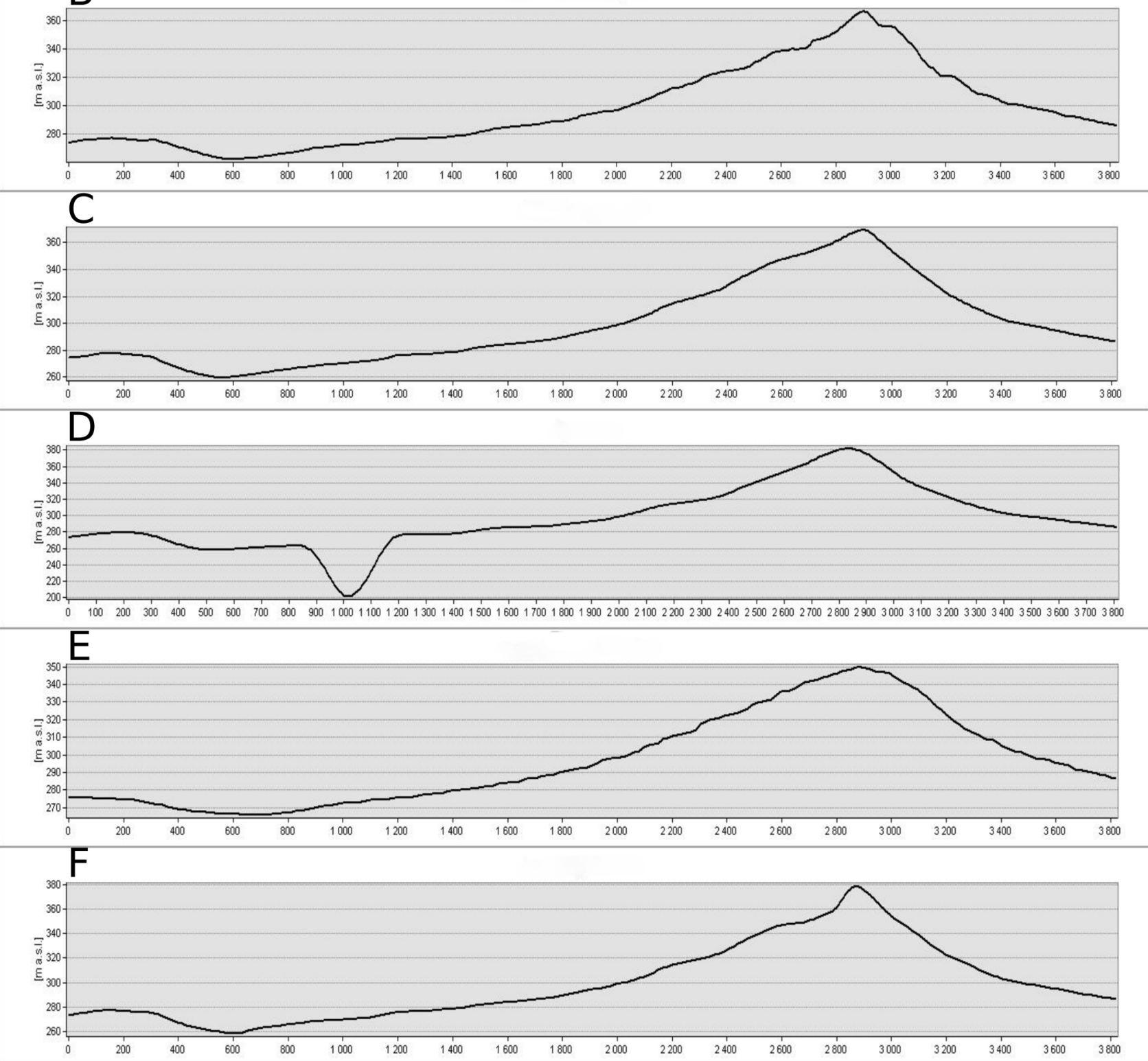

G

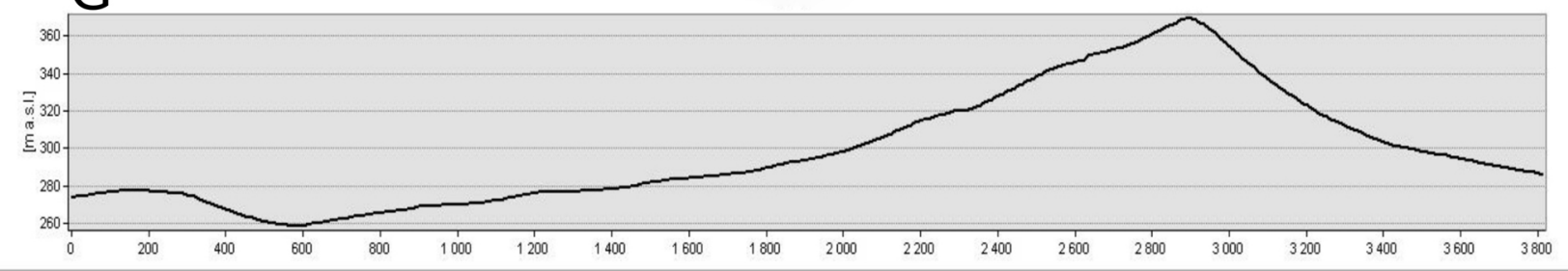

Fig. 6. Profile line in interpolated DEMs: A - LiDAR DEM, B - IDW, C - Natural Neighbour, D - Spline, E - Radial Basis Functions, F - Local Polynomial, G - Kriging 
Table 6. Geomorphometric variable statistics for the DEMs obtained in different interpolation methods

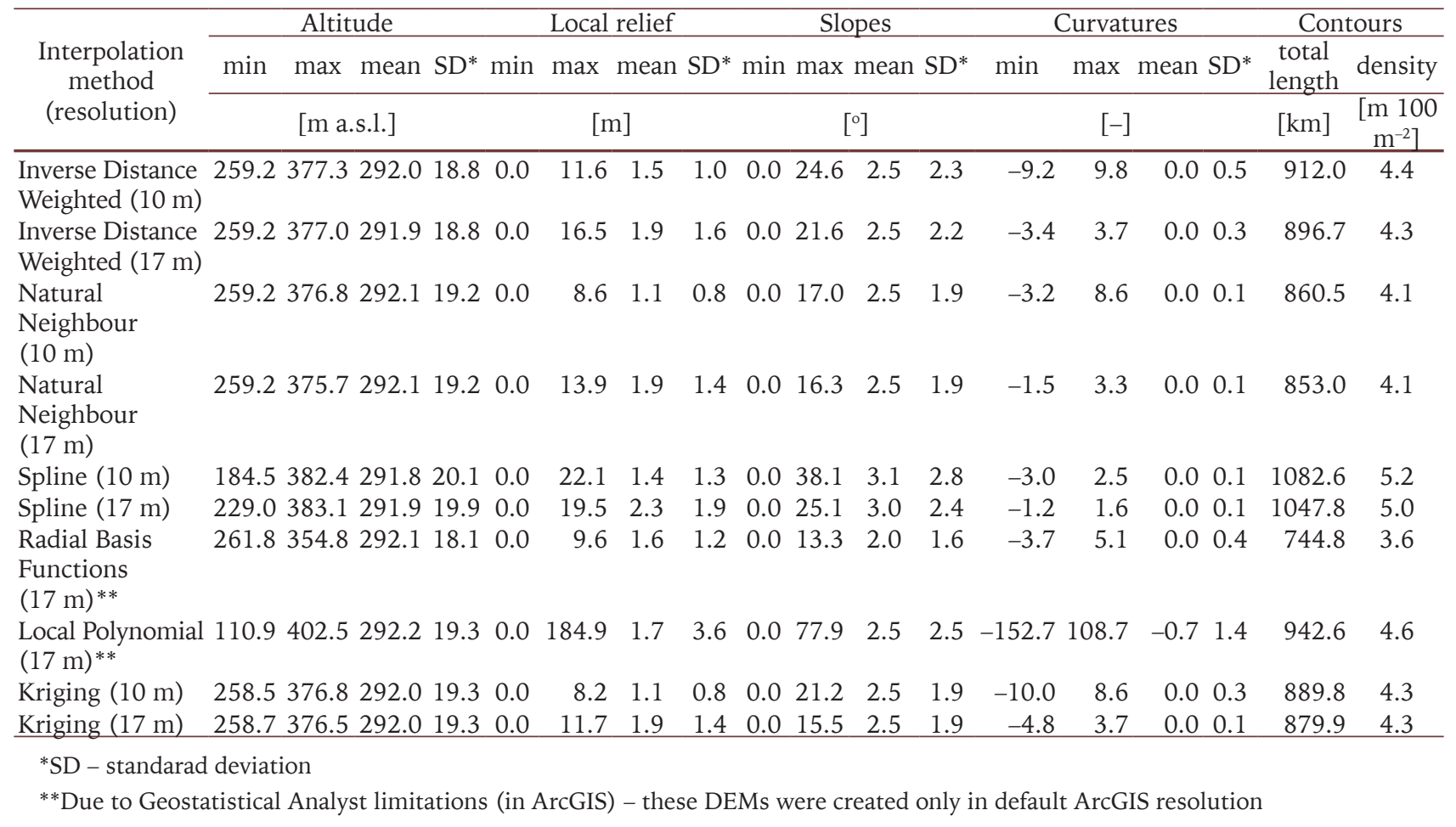

The curvature function displays the shape or curvature of the slope. The curvature values in Table 6 combines both the profile and planform curvatures. This is a general measure of the convexity of the landscape, where sinks and valleys are considered concave and peaks and high points are considered convex. Convex surfaces have positive values and concave surfaces have negative values. A general curvature value near zero indicates either a flat area or an area where the convexity in one direction is balanced by the concavity in the perpendicular direction, such as on a saddle (Jenness 2013). The biggest negative curvature values demonstrates Kriging model (-4.8), Radial Basis Functions (-3.7) and Inverse Distance Weighted (-3.4), indicating local con- cave surfaces. The biggest positive curvature values shows Radial Basis Functions model (5.1), it is probably the result of lumps that occur on the surface of the model.

Next variable were contour lines. Total length of the contour lines ranged from $745 \mathrm{~km}$ (Radial Basis Functions) to $897 \mathrm{~km}$ (Inverse Distance Weighted) (Table 6). This shows that the Radial Basis Function model is the most smooth - at least when it comes to plan curvatures. The derivative of the total length of the contour lines is their density $\left(\mathrm{m} 100 \mathrm{~m}^{-2}\right)$ which

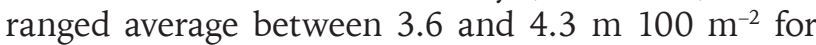
the entire area. Due to the previously mentioned artefacts - Spline and Local Polynomial models are heavily inflated the value of contour lines.

Table 7. Aspect statistics of the DEMs

\begin{tabular}{|c|c|c|c|c|c|c|c|c|}
\hline \multirow{2}{*}{ Interpolation method (resolution) } & \multicolumn{8}{|c|}{$\%$ of main aspect directions } \\
\hline & $\mathrm{N}$ & $\mathrm{NE}$ & $\mathrm{E}$ & SE & S & SW & $\mathrm{W}$ & NW \\
\hline LiDAR DEM (1 m) & 11.0 & 12.3 & 13.7 & 14.5 & 15.4 & 13.2 & 10.6 & 9.4 \\
\hline Inverse Distance Weighted (10 m) & 8.7 & 10.6 & 15.9 & 18.0 & 16.0 & 11.4 & 11.0 & 8.4 \\
\hline Inverse Distance Weighted (17 m) & 8.5 & 10.6 & 16.0 & 18.2 & 16.0 & 11.3 & 11.0 & 8.3 \\
\hline Natural Neighbour (10 m) & 8.0 & 10.4 & 16.8 & 18.7 & 15.8 & 11.7 & 10.7 & 7.6 \\
\hline Natural Neighbour (17 m) & 7.9 & 10.2 & 16.6 & 18.5 & 15.5 & 11.6 & 10.6 & 7.5 \\
\hline Spline $(10 \mathrm{~m})$ & 9.6 & 11.7 & 15.5 & 15.7 & 17.1 & 12.3 & 10.2 & 7.9 \\
\hline Spline $(17 \mathrm{~m})$ & 9.5 & 11.7 & 15.3 & 16.0 & 17.5 & 11.9 & 10.0 & 8.0 \\
\hline Radial Basis Functions (17 m) & 7.9 & 9.2 & 17.2 & 19.3 & 15.3 & 11.7 & 11.4 & 8.0 \\
\hline Local Polynomial (17 m) & 8.2 & 10.9 & 16.1 & 18.9 & 15.7 & 11.6 & 10.9 & 7.7 \\
\hline Kriging $(10 \mathrm{~m})$ & 8.3 & 10.3 & 16.3 & 18.9 & 16.0 & 11.9 & 10.6 & 7.7 \\
\hline Kriging $(17 \mathrm{~m})$ & 8.2 & 10.2 & 16.3 & 19.0 & 16.0 & 11.9 & 10.6 & 7.7 \\
\hline Mean (without LiDAR DEM) & 8.5 & 10.6 & 16.2 & 18.0 & 16.1 & 11.7 & 10.7 & 7.9 \\
\hline
\end{tabular}


The last analysed geomorphometric variable was aspect. Table 7 shows the percentages of aspect for 8 basic directions. The most represented directions were SE (15.7-19.0\%), E (15.3-17.2\%) and S (15.3$17.5 \%)$ and the least NW (7.5-8.4\%) and N (7.9$9.6 \%)$. So it can be observed that the study area is the predominant E, SE and S aspect. Differences in the same direction for different DEMs (with $17 \mathrm{~m}$ resolution) are from 0.8 to $3.3 \%$, but usually $1.5-2.0 \%$. These differences are statistically insignificant and do not affect the general characteristics of the relief of the area. So, one can say that all tested interpolation methods coped successfully well with mapping of aspects.

\section{Vertical accuracy of DEMs}

The quality of the DEMs is essential for assessing their suitability and determines the quality of the geomorphometric (and geomorphological) analysis (Shearer 1990, Desmet 1997, Chaplot et al. 2006, Reuter et al. 2009). Small errors in DEMs can produce large errors in derived values, especially second-order derivatives such as curvature (Florinsky 2002, Wise 1998). For the geomorphometric purposes it is extremely important the elevation accuracy, which is estimated by calculating the error. The error is the difference between elevation value from DEM and real elevation value. In this study, real elevation values represent LiDAR DEM mentioned above. The most commonly used measure of DEM quality, and the one published by data suppliers, is the Root Mean Square Error (RMSE). The RMSE is also an important parameter which is frequently used in GIS. The RMSE is used as an indicator of the accuracy of the spatial analysis. The RMSE is a measure of the differences between two datasets (DEMs). Each individual difference between the calculated and actual value is called a residual. The RMSE aggregates the residuals into a single measure. The RMSE is derived by squaring the dif- ferences between the actual and calculated values, adding these residuals together, dividing that by the total number of values, and taking the square root of the result. The RMSE is calculated as shown below (Wise 2011):

$$
R M S E_{\text {elev }}=\sqrt{\frac{\sum\left(z_{p}-z_{o}\right)^{2}}{n}}
$$

where:

$z_{p}$ is the predicted elevation,

$z_{0}$ the actual (observed) elevation.

I estimated elevation accuracy of each interpolated DEM comparing it with the LiDAR DEM. The first - Root Mean Square Error values on the basis of all grid values of every DEMs were calculated. The results are shown in Table 8. As one can see the greatest RMSE value is related to the Radial Basis Functions model $(3.7 \mathrm{~m})$, and the smallest - to the Local Polynomial $(1.5 \mathrm{~m})$. The RMSE in other DEMs varies $2-3 \mathrm{~m}$. One should remember, that RMSE is averaged value and spread over the entire DEM (cellby-cell difference), so in this case the values $\geq 2.5 \mathrm{~m}$ are a relatively big errors.

When we look at the 'Difference' column in Table 8 we will see that the greatest differences in elevations are present in the Local Polynomial model $(-115$ and $+181 \mathrm{~m})$ and Spline $(-23$ and $+86 \mathrm{~m})$, but after the visual assessment of these models in 3D tool (ArcScene) we remember that these errors are one-time local artefacts (see black circles on Fig. 7C and $\mathrm{E})$. The spatial distribution of the biggest positive differences in the models is associated with the highest places, and the biggest negative differences - with concave areas. Only in the Spline model the biggest positive differences found in the former excavation of sand, and the biggest negative differences - on a flat area.

The last thing to be considered was the result conformity of the elevations between DEMs. Result conformity values express how many percent of the grid

Table 8. Comparing interpolated DEMs with LiDAR DEM

\begin{tabular}{|c|c|c|c|c|}
\hline \multirow{2}{*}{ Interpolation method } & \multirow{2}{*}{ RMSE $[\mathrm{m}]$} & \multicolumn{2}{|c|}{ Elevation difference $[\mathrm{m}]$} & \multirow{2}{*}{ Result conformity* [\%] } \\
\hline & & $\min$ & $\max$ & \\
\hline Inverse Distance Weighted (10 m) & 2.86 & -16.7 & 26.5 & 7.5 \\
\hline Inverse Distance Weighted (17 m) & 2.86 & -16.7 & 24.9 & 7.2 \\
\hline Natural Neighbour (10 m) & 1.97 & -13.4 & 19.2 & 11.1 \\
\hline Natural Neighbour (17 m) & 1.99 & -12.9 & 18.1 & 10.6 \\
\hline Spline $(10 \mathrm{~m})$ & 3.06 & -23.0 & 86.3 & 10.4 \\
\hline Spline (17 m) & 2.35 & -24.1 & 41.3 & 10.4 \\
\hline Radial Basis Functions (17 m) & 3.66 & -16.5 & 33.2 & 4.0 \\
\hline Local Polynomial (17 m) & 1.54 & -115.4 & 181.0 & 10.3 \\
\hline Kriging $(10 \mathrm{~m})$ & 1.91 & -12.3 & 18.2 & 11.8 \\
\hline Kriging (17 m) & 1.91 & -11.8 & 17.4 & 11.5 \\
\hline
\end{tabular}

*Result conformity was calculated as $\pm 0.1 \mathrm{~m}$ identical with LiDAR DEM heights 


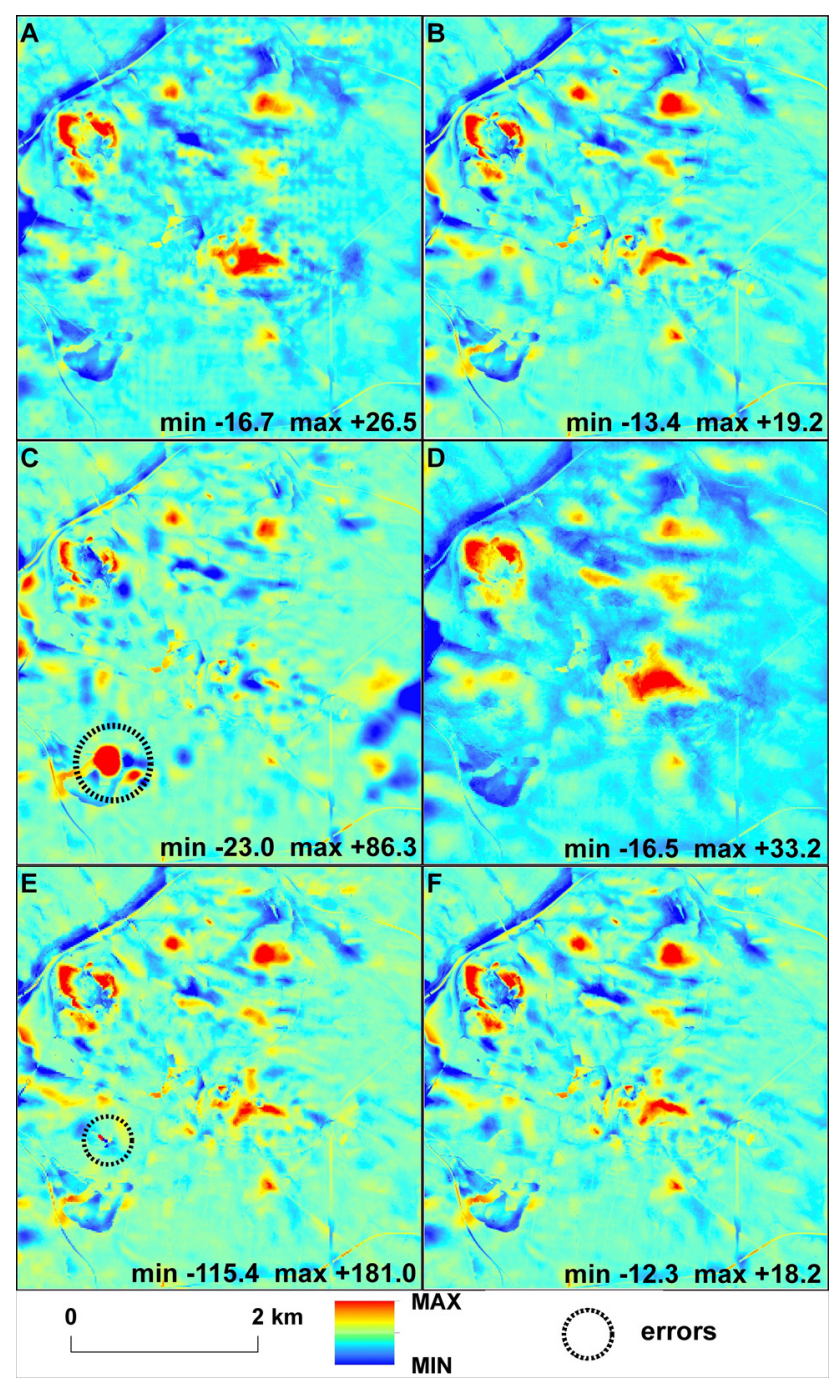

Fig. 7. Differences in meters between LiDAR DEM and interpolated DEMs: A - IDW, B - Natural Neighbour, C Spline, D - Radial Basis Functions, E - Local Polynomial, $\mathrm{F}$ - Kriging

cells of interpolated DEM are in accordance with the same grid cells of the LiDAR DEM, within accuracy of $\pm 0.1 \mathrm{~m}$. Table 8 shows that the highest elevation compliance demonstrated Kriging (almost 12\%), and Natural Neighbour, Spline and Local Polynomial held over $10 \%$, the IDW method contained about $7 \%$ and the least Radial Basis Function, only $4 \%$.

\section{Conclusions}

My research lead to the following conclusions:

1. All interpolation methods (except Spline and IDW) overstate the terrain heights in the places of the main elevations, and underestimate in the lowest places. This causes the accentuating (enhancing) of the relief of the analysed area.
2. The Spline method showed the greatest positive differences in the sand excavation and negative differences - on a flat area; turn in the highest elevations - differences reached few meters (plus or minus). So one can say, that this method, except for artefacts which may occur, generally smoothes the relief.

3. There were the biggest errors in Spline and Local Polynomial methods. These errors are a number of local artefacts of a different elevation than real (from -115 to $+181 \mathrm{~m}$ ). However, taking into account the RMSE values (from 1.5 to $3.0 \mathrm{~m}$ ) and result conformity of elevation with LiDAR DEM values (see Table 8 ) it must be recognized, that both methods well characterized of the morphology in the geomorphometric meaning.

4. All used interpolation techniques very well handled quantitative aspect characteristics of the study area. Regardless of the used method or resolution - the differences in percentage shares for the same aspect comparing with the LiDAR DEM were up to $3.5 \%$, and usually less than $2 \%$.

5. It turned out that the IDW, Natural Neighbours and Kriging models created in two different resolutions (10 and $17 \mathrm{~m}$ ) had surprisingly similar geomorphometric variable values (see Table 5). The values of altitude, contour lines and the average true heights, slopes and curvatures were the same or nearly the same in both resolutions. The maximum true heights were greater in the $17 \mathrm{~m}$ models (which is apparent from the fact of taking into account the larger area for the calculations), and the maximum slope and curvature values are larger in the models of $10 \mathrm{~m}$ (which is also consistent with the observations, because a smaller field of analysis results a larger variety of curves, i.e. the smaller slope averaging).

6. After conducted studies - visual assessment of 3D models, comparing of geomorphometric variables, vertical accuracy and result conformity with the LiDAR DEM - it should be noted, that the best interpolation methods for analyse of the relief turned out to be the Natural Neighbour and Kriging. These models due to a lower resolution (than LiDAR DEM) are much less detailed, but did not create any artefacts. Although both methods are different in terms of handling (Natural Neighbour is simple and intuitive to use, and the only required input data are point elevation data, while Kriging is a powerful geostatistical tool with many definable parameters) they are both great coped successfully with properly relief mapping of the study area.

7. One can say, that in order to properly describe the relief of the selected area (on account of geomorphometric properties) it is not necessary to use 
huge sets of points derived from ALS (we say here about situation from geomorphological point of view). Sometimes one can thin the point clouds and leave points, spaced more or less regularly on the whole study area, with interval approx. $100 \mathrm{~m}$ among them, but still correctly reflecting the relief of any area (see Table 1 vs Table 2 ) in the given scale of accuracy. LiDAR data, with density up to $12 \mathrm{pts} \mathrm{m}^{-2}$, obviously allow to create a model with a resolution of $0.5 \times 0.5 \mathrm{~m}$, while the data of the average density of $64 \mathrm{pts} \mathrm{km}^{-2}$ make possible to create a model with a maximum resolution of $10 \times 10$ m (i.e. 400 times less resolution!). Undoubtedly, this is important when analysing very small forms (microrelief), but in standard geomorphological research is not necessary.

\section{Acknowledgements}

Sincere thanks to all reviewers for many valuable comments that made this paper much better.

\section{References}

ANU Fenner School of Environment and Society and Geoscience Australia 2008. Geodata 9 Second Digital Elevation Model Version 3 and Flow Direction Grid, User Guide. Geoscience Australia. $43 \mathrm{p}$.

ASPRS (American Society for Photogrammetry and Remote Sensing), 2008. LAS Specification version 1.2. $13 \mathrm{p}$.

Biernat S., 1955. Szczegółowa mapa geologiczna Polski, 1:50,000, arkusz M-34-51-C Wojkowice. Instytut Geologiczny.

Carlson R.E., Foley T.A., 1991. Radial Basis Interpolation Methods on Track Data. Lawrence Livermore National Laboratory, UCRL-JC-1074238.

Carrara A., Bitelli G., Carla, R., 1997. Comparison of techniques for generating digital terrain models from contour lines. International Journal of Geographical Information Science 11 (5): 451-473. DOI: 10.1080/136588197242257.

Chaplot V, Darboux F, Bourennane H, Leguédois S, Silvera N, Phachomphon K. 2006. Accuracy of interpolation techniques for the derivation of digital elevation models in relation to landform types and data density. Geomorphology 77: 126-141. DOI: 10.1016/j.geomorph.2005.12.010.

Childs C., 2004. Interpolating Surfaces in ArcGIS Spatial Analyst [online]. ArcUser Online July - September. Online: https:// www.esri.com/news/arcuser/0704/files/interpolating.pdf 30.10.2015.

CODGiK, 2015. Numeryczne dane wysokościowe. Online: http://www.codgik.gov.pl/index.php/zasob/numeryczne-dane-wysokosciowe.html - 30.10.2015.

Declercq F.A.N., 1996. Interpolation methods for scattered sample data: accuracy, spatial patterns, processing time. Cartography and Geographical Information Systems 23(3): 128-44.

Desmet P.J.J., 1997. Effects of interpolation errors on the analysis of DEMs. Earth Surface Processes and Landforms 22: 563-580. DOI: $\quad 10.1002 /(\mathrm{SICI}) 1096-9837(199706) 22: 6<563:: A I D-E S-$ P713>3.0.CO;2-3.

Erdogan S., 2009. A comparison of interpolation methods for producing digital elevation models at the field scale. Earth Surface Processes and Landforms 34: 366-376. DOI: 10.1002/esp.1731.
ESRI (Environmental Systems Research Institute), 2015. ArcGIS 10.3.1 for Desktop Help.

Farr T.G., Rosen P.A., Caro E., Crippen R., Duren R., Hensley S., Kobrick M., Paller M., Rodriguez E., Roth L., Seal D., Shaffer S., Shimada J., Umland J., Werner M., Oskin M., Burbank D., Alsdorf D.E., 2007. The shuttle radar topography mission. Reviews of Geophysics 45, RG2004. DOI: 10.1029/2005RG000183.

Florinsky I.V., 1998. Accuracy of local topographic variables derived from digital elevation models. International Journal of Geographical Information Science 12 (1): 47-62. DOI $10.1080 / 136588198242003$.

Florinsky I.V., 2002. Errors of signal processing in digital terrain modelling. International Journal of Geographical Information Science 16 (5): 475-501. DOI: 10.1080/13658810210129139.

Gilewska S., 1986. Podział Polski na jednostki geomorfologiczne. Przegląd Geograficzny LVIII(1-2): 15-40.

Hengl T., 2006. Finding the right pixel size. Computers \& Geosciences 32: 1283-1298. DOI: 10.1016/j.cageo.2005.11.008.

Isaaks M, Srivastava R.M., 1989. An Introduction to Applied Geostatistics. Oxford University Press: New York.

Jenness J., 2013. DEM Surface Tools. Jenness Enterprises. 98 p. Online: http://www.jennessent.com/downloads/DEM\%20Surface\%20Tools\%20for\%20ArcGIS.pdf - 30.10.2015.

Karaś-Brzozowska C., 1960. Charakterystyka geomorfologiczna Górnośląskiego Okręgu Przemysłowego. In: Klimaszewski M. (ed.), Biuletyn 37, PAN, Warszawa. 210 p.

Kemp K.K. (ed.), 2008. Encyclopedia of Geographic Information Science. SAGE Publications Inc. 558 p. DOI: 10.4135/9781412953962.

Kondracki J., 2001. Geografia regionalna Polski. Warszawa: PWN. $441 \mathrm{p}$.

Kozieł Z., 2003. Geokompozycyjno-wizualizacyjne aspekty modelowania rzeźby terenu wobec współczesnych procedur pozyskiwania i przetwarzania danych. Uniwersytet im. M.Kopernika, Torun. 240 p.

Li Z., Zhu Q., Gold C., 2005. Digital terrain modeling - principles and methodology. New York: CRC Press. 324 p.

Mapa Topograficzna, 1:10 000, 1993, arkusz M-34-51-C-c-4 Będzin Grodziec. Główny Geodeta Kraju.

Mitas L., Mitasova H., 1988. General Variational Approach to the Interpolation Problem. Computer and Mathematics with Applications 16(12): 983-992.

Mitas L., Mitasova H., 1999. Spatial interpolation. In: Longley P., Goodchild M.F., Maguire D.J., Rhind D.W. (eds), Geographical Information Systems: Principles, Techniques, Management and Applications, vol. 1. Wiley: 481-492.

Nering K., 2009. SRTM - Earth surface imaging technique. Technical Transactions, Environmental Engineering, 1-Ś/2009: 97106.

Oliver M. A., 1990. Kriging: A Method of Interpolation for Geographical Information Systems. International Journal of Geographic Information Systems 4: 313-332.

Pike R.J., Evans I.S., Hengl T., 2009. Geomorphometry: a Brief Guide. In: Hengl T., Reuter H.I. (eds), Geomorphometry: Concepts, Software, Applications. Developments in Soil Science 33, Elsevier, Amsterdam: 3-30. DOI: 10.1016/S01662481(08)00001-9.

Reuter H.I., Hengl T., Gessler P., Soille P., 2009. Preparation of DEMs for Geomorphometric Analysis. In: Hengl, T., Reuter, H.I. (eds), Geomorphometry: Concepts, Software, Applications. Developments in Soil Science 33, Elsevier, Amsterdam: 87-120. DOI: 10.1016/S0166-2481(08)00004-4.

Royle A.G., Clausen F.L., Frederiksen P., 1981. Practical Universal Kriging and Automatic Contouring. Geoprocessing 1: 377-394.

Shearer J.W., 1990. The accuracy of digital terrain models. In: Petrie G., Kennie T.J.M. (eds), Terrain Modeling in Surveying and Engineering. Whittles Publishing Services: Caithness: 315-336.

Sibson R., 1981. A Brief Description of Natural Neighbor Interpolation. In: Interpolating Multivariate Data. Chapter 2. John Wiley \& Sons, New York: 21-36. 
Sinha P., Verma N.K., Rao L.I.M., Singh A.N., 2002. Surface Approximation of Point Data using different interpolation techniques - A GIS Approach. Map Asia - 2002 International Conference on "GIS/GPS, Aerial Photography and Remote Sensing", 7-9 August 2002 Bangkok, Thailand.

Tobler W., 1970. A computer movie simulating urban growth in the Detroit region. Economic Geography 46(2): 234-240.

Wehr A., Lohr U., 1999. Airborne laser scanning - an introduction and overview. ISPRS Journal of Photogrammetry and Remote Sensing 54(2-3): 68-82.

Weibel R., Heller M., 1991. Digital terrain modelling. In: Maguire D.J., Goodchild M.F., Rhind D.W. (Eds.), Geographical Information Systems, vol. 1. Longman, Harlow: 269-297.

Wężyk P. (ed.), 2014. Podręcznik dla uczestników szkoleń z wykorzystania produktów LiDAR. Warszawa: GUGiK, 328 p.

Wilson J.P., Gallant J.C. (eds), 2000. Terrain Analysis. Principles and Applications. John Wiley and Sons, New York: 479 p.

Wise S.M., 1998. The effect of GIS interpolation errors on the use of DEMs in geomorphology. In: Lane S.N., Richards K.S., Chan- dler J.H. (eds), Landform Monitoring, Modeling and Analysis. Wiley, Chichester: 139-164.

Wise S.M., 2007. Effect of differing DEM creation methods on the results from a hydrological model. Computers \& Geosciences 33(10): 1351-1365. DOI: 10.1016/j.cageo.2007.05.003.

Wise S.M., 2011. Cross-validation as a means of investigating DEM interpolation error. Computers \& Geosciences 37(8): 978-991. DOI: 10.1016/j.cageo.2010.12.002.

Wood J.D., Fisher P.F., 1993. Assessing interpolation accuracy in elevation models. IEEE Computer Graphics and Applications 13(2): 48-56. DOI: 10.1109/38.204967.

Yang C.S., Kao S.P, Lee F.B., Hung P.S., 2004. Twelve Different Interpolation Methods: a Case Study of Surfer 8.0. ISPRS Archives, International Archives of Photogrammetry 35 PtB2: 778-785.

Yilmaz H.M., 2007. The effect of interpolation methods in surface definition: an experimental study. Earth Surface Processes and Landforms 32(9): 1346-1361. DOI: 10.1002/esp.1473.

Zimmerman C., Pavlik A., Ruggles A., Armstrong M., 1999. An experimental comparison of ordinary and universal kriging and inverse distance weighting. Mathematical Geology 31: 375-390. 